\title{
Sentidos da participação social na saúde para lideranças comunitárias e profissionais da Estratégia Saúde da Família do território de Vila União, em Sobral-CE
}

\section{| ${ }^{1}$ Fabiana Araújo Lima, ${ }^{2}$ Percy Antonio Galimbertti |}

Resumo: O artigo apresenta um estudo de caso com abordagem qualitativa que teve como objetivo analisar os sentidos da participação social na saúde para lideranças comunitárias e profissionais da Estratégia Saúde da Família (ESF) do território de Vila União em Sobral, Ceará. Os dados foram coletados mediante grupos focais e submetidos à Análise de Conteúdo. Os resultados evidenciaram que os sentidos produzidos social e historicamente para participação social, reconhecida como conquista e direito, estão associados ao engajamento, à transformação social, ao comprometimento em busca de melhorias comunitárias, à ação/intervenção social, ao protagonismo, à construção coletiva e mobilização, à solidariedade comunitária e à educação libertadora. A pesquisa proporcionou aproximação aos sentidos da participação na ESF e apresentou entraves que são inerentes à vida política do país e estão diretamente relacionados à construção do Sistema Único de Saúde (SUS). Consideramos imprescindível a construção de um novo modelo de atenção à saúde pautado na participação social e que aponte para uma rede de compromissos e laços de afetividade potentes com o SUS/ESF e que possa implicar, sobretudo, a comunidade.

> Palavras-chave: participação social; Sistema Único de Saúde; atenção primária; saúde da família.

\footnotetext{
1 Universidade Federal do Ceará, Mestrado Acadêmico em Saúde da Família. Sobral-CE, Brasil (fabianabrafor@hotmail.com).

2 Universidade Federal do

Ceará, Faculdade de Medicina. Sobral-CE, Brasil (galimbertti@ ufc.br).
} 


\section{Introdução}

No contexto brasileiro, os processos de participação social foram se constituindo historicamente em um cenário de opressão e resistência. De acordo com Soares (2012), a crise estrutural do capital mundial, a partir da década de 70, contribuiu significativamente para o fim do regime autocrático instaurado em 1964 com a ditatura militar e com a institucionalização política e legal de muitas reinvindicações dos movimentos sociais na Constituição Federal (CF) de 1988, dentre elas, o Sistema Único de Saúde (SUS).

O Movimento de Reforma Sanitária foi interlocutor da luta pelo direito universal pela saúde, democratização do Estado brasileiro e por uma política que superasse o modelo autoritário e fragmentado da política social (SOARES, 2012). Destarte, com o advento da nova CF, a saúde foi considerada como direito de todos e dever do Estado (Art. 196) e em seu conteúdo foram adotados os conceitos e pressupostos elaborados na $8^{\text {a }}$ Conferência Nacional de Saúde, criando o SUS, regido pelos princípios doutrinários de universalidade, equidade integralidade e princípios organizativos, a exemplo da participação social (ESCOREL, 2008). Assim, a saúde foi inscrita em um sistema de seguridade social com a garantia do controle social por meio do princípio da "participação popular" e de duas instâncias formais: os conselhos e as conferências (MENEZES, 2012).

Cabe destacar que essas não são as únicas possibilidades de participação, mas se configuram como mecanismos fundamentais e legais garantidos pela CF e pela Lei no 8.142/1990, que trata da participação da comunidade na gestão do SUS. Entretanto, conforme relata Menezes (2012), o controle democrático está para além da atuação dos segmentos sociais no espaço institucional dos conselhos.

$\mathrm{Na}$ Lei no 8.142/1990, a participação social adquire um sentido político, ao conferir caráter deliberativo aos conselhos de saúde. Contudo, sua prática está envolvida num processo contraditório de conquista e outorga, pois, embora tenha sido estabelecida a partir de processo de luta, em muitas realidades locais, configuram-se como espaços de imposição legal de gestores limitando a autonomia (OLIVEIRA; PINHEIRO, 2010).

No cenário contraditório destacado, a articulação entre comunidade, famílias e promoção da saúde passou a ser significativa para fomentar a participação social no SUS. Foi implantado assim, na década de 1990, o Programa Saúde da Família, posteriormente transformado em Estratégia Saúde da Família (ESF), um modelo 
de Atenção Primária à Saúde instituído para estruturar, orientar e direcionar o modelo de atenção à saúde no Brasil (GIOVANELLA; MENDONÇA, 2008; ANDRADE et al., 2012).

No âmbito das políticas públicas voltadas para o fortalecimento e revitalização da Atenção Básica e consequentemente do SUS, destaca-se a Política Nacional de Atenção Básica (PNAB), lançada pela Portaria no 648/GM, de 28 de março de 2006. Essa política foi atualizada pela Portaria no 2.488, em 21 de outubro de 2011, permanecendo em consonância com os princípios do SUS e mantendo a participação como um de seus princípios orientadores. A PNAB de 2011 definiu a participação social como um de seus fundamentos e diretrizes, visando ampliar a autonomia dos usuários, bem como sua capacidade de construção do cuidado à sua saúde, no enfrentamento dos determinantes e condicionantes de saúde no território e na organização e orientação dos serviços de saúde centrada no usuário e no exercício do controle social (BRASIL, 2012).

Este artigo dialoga com discursos acerca da participação social apresentados por Demo e Brandão. Para Demo (1996), a participação se configura como conquista e, em essência, é autopromoção. Conquista, pois significa processo, no sentido legítimo do termo: infindável, em constante vir-a-ser, sempre se constituindo.

Já Brandão (2008) destaca que participar é, sem dúvida, exercer o poder, expressar livremente a potência de ação. Entender a participação como potência implica também perceber que ela não é um processo exclusivamente racional, pois não há causalidade determinista entre conscientização e ação transformadora. É algo inerente ao ser humano quando pensada como forma de poder/potência e deve ser compreendida como práxis crítica transformadora que se institui como expressão do pensamento e do afeto.

Apesar dos esforços governamentais em desenvolver políticas para contribuir com a efetivação da participação social na saúde, muitos ainda são os entraves quando confrontamos com as realidades locais, permeadas de desigualdades estruturantes que limitam o exercício da cidadania e que estão refletidas no cotidiano dos serviços de saúde e na vida comunitária.

$\mathrm{O}$ artigo em questão apresenta sentidos da participação social na saúde para lideranças comunitárias e profissionais da ESF do território de Vila União, em Sobral-CE. É um recorte de uma pesquisa mais ampla de dissertação de mestrado intitulada "Participação social na Estratégia Saúde da Família: um estudo de caso 
no Território de Vila União em Sobral-CE", que teve como objetivo principal analisar percepções de lideranças comunitárias e profissionais de saúde sobre a participação social na ESF do território de Vila União em Sobral-CE.

\section{Metodologia}

O estudo teve abordagem qualitativa e buscou explorar e entender sentidos atribuídos por lideranças comunitárias e profissionais de saúde sobre participação social na ESF de Vila União em Sobral-CE.

Segundo Minayo (2001; 2008), o método qualitativo se aplica ao estudo da história, das relações, das percepções, produtos das interpretações que os humanos fazem a respeito de como vivem, sentem e pensam. Trabalha com o universo de significados, valores e atitudes, o que corresponde a um espaço profundo das relações que não podem ser quantificadas.

O estudo qualitativo foi materializado por meio de uma pesquisa social de campo do tipo exploratório-descritivo, considerada uma investigação empírica cujo objetivo é a formulação de questôes ou de problema, que tem dentre outras finalidades aumentar a familiaridade do pesquisador com um ambiente, fato ou fenômeno, bem como modificar e clarificar conceitos (LAKATOS; MARCONI, 2005).

Para exploração em campo, foi realizado um estudo de caso, estratégia de pesquisa abrangente que permite investigação empírica para apreender as características significantes e holísticas de eventos contemporâneos da vida real (YIN, 2001). O estudo de caso é uma forma de investigar o real, onde se coletam e registram dados para posterior interpretação e reconstrução em bases científicas. Sua importância está no fato de romper com o senso comum e promover um processo de compreensão dos elementos investigados em sua profundidade (MARTINELLI, 1999). Nesse contexto, foi realizado um estudo de caso acerca da participação social na ESF, tendo como unidade de análise o território de Vila União em Sobral-CE.

A pesquisa ocorreu entre 2012 e 2014, no território de Vila União no município de Sobral, estado do Ceará, tendo como referência o Centro de Saúde da Família (CSF). Esse estado tem população estimada de 8.778 .575 e possui 184 municípios. O município de Sobral tem extensão territorial de 2.129,989 km² e população estimada de 197.663 habitantes (IBGE, 2013). 
Tendo como referência o mês de abril de 2014, Sobral possui cobertura de Atenção Básica de 91,91 \% e 59.685 famílias cadastradas no Sistema de Informação da Atenção Básica (SIAB). Conta com 37 CSFs cadastrados no Sistema de Cadastro Nacional de Estabelecimentos de Saúde (SCNES). Possui 401 agentes comunitários de saúde (ACS), 56 equipes de Saúde da Família, seis equipes de Núcleos de Apoio à Saúde da Família (NASF) e 37 equipes de Saúde Bucal. De acordo com fontes do SIAB (abril/2014) em Sobral, o CSF de Vila União possui duas equipes de Saúde da Família cadastradas que acompanham 8.376 pessoas (4.157 do sexo masculino e 4.219 do sexo feminino), totalizando 2.198 famílias.

Para realização desta pesquisa no cenário apresentado, utilizou-se como técnica fundamental para construção dos dados empíricos, o grupo focal com lideranças comunitárias e profissionais de saúde.

Cruz Neto, Moreira e Sucena (2002) conceituam grupo focal como uma técnica de pesquisa na qual o pesquisador reúne determinada quantidade de pessoas que são sujeitos da investigação num mesmo local e durante certo período, com o objetivo de coletar, a partir do diálogo e do debate com e entre eles, informaçōes acerca de um tema específico. $\mathrm{O}$ grupo focal trabalha com a reflexão expressa na fala dos participantes, permitindo que eles apresentem conceitos, impressões e concepções sobre determinado tema produzindo informações de cunho qualitativo.

Com relação aos participantes deste estudo, segundo Minayo (2006), nas pesquisas qualitativas, o pesquisador pode selecionar participantes representativos em relação ao objeto do estudo. Segundo Cruz Neto, Moreira e Sucena (2002), o número de grupos focais também a ser realizado não é rigidamente determinado por fórmulas matemáticas, mas pelo esgotamento dos temas, não se prendendo, portanto, a relações de amostragem. Assim, a proposta para esta pesquisa foi construir grupos homogêneos, com características semelhantes em termos de contexto de trajetória profissional e/ou comunitária, sendo realizados três grupos divididos entre lideranças comunitárias e profissionais de saúde. Os participantes foram agrupados da seguinte maneira:

- Grupo 1: lideranças comunitárias - 17 participantes;

- Grupo 2: gerente do CSF, apoiadora institucional e equipe multiprofissional - Residência Multiprofissional em Saúde da Família (RMSF) e NASF - 10 participantes;

- Grupo 3: agentes comunitários de saúde, médica e dentista - 11 participantes. 
Para subsidiar a realização dos grupos focais e a análise das informações obtidas, aprofundou-se a revisão de bibliografia. A pesquisa bibliográfica configura-se como um apanhado geral sobre os principais trabalhos já realizados e capazes de fornecer dados atuais e relevantes sobre a temática em questão (LAKATOS; MARCONI, 2005). O estudo da literatura possibilitou uma fonte indispensável de informações que contribuiu na fundamentação das reflexões e interpretações das falas coletadas em campo.

Após o processo de obtenção das informações, as mesmas foram submetidas à análise de conteúdo, que segundo Bardin (1977), é um conjunto de técnicas de análise das comunicaçôes que procura estabelecer uma correspondência entre as estruturas semânticas ou linguísticas e as estruturas psicológicas ou sociológicas dos enunciados. Dentre as várias modalidades de análise de conteúdo, utilizamos a análise temática. De acordo com Bardin (2002), a análise temática baseiase em operaçôes de desmembramento do texto em unidades, ou seja, descobrir os diferentes núcleos de sentido que constituem a comunicação, e realizar seu reagrupamento em categorias. Nessa perspectiva, foram seguidas etapas propostas por Bardin (1977) e Minayo (2008) que compreendiam fases de pré-análise, exploração do material e tratamento dos resultados e interpretação.

O estudo buscou obedecer aos preceitos éticos da pesquisa envolvendo seres humanos estabelecidos pela Resolução no 466, de 12 de dezembro de 2012. Foi submetido a todas as instâncias éticas necessárias para cumprimento dos trâmites legais e sociais para sua realização e obteve aprovação do Comitê de Ética e Pesquisa (CEP) junto à Plataforma Brasil sob o no 638.825 e CAAE 25742714.6.0000.5053.

Para manter o sigilo dos(as) participantes do estudo e salvaguardar seus nomes, todos os discursos foram codificados por letras alfabéticas. Com relação aos ACS, optamos por identificá-los ao lado da letra para valorizar seus discursos e suas experiências.

\section{Resultados e discussão}

A participação é um referencial de conquista da humanidade por aqueles que lutam por seus direitos, por aquelas pessoas que buscam pela sua liberdade e pelos seus objetivos na sociedade (PROFISSIONAL A - ACS). 
A participação social está ligada à construção de sentidos pelos sujeitos e não

pode ser percebida como algo dado ou mera normatização, mas como conquista. Assim, para Brandão (2008), o que faz sentido é o que mexe com a consciência, compreendida como um sistema dinâmico. É o sentido que nos humaniza e nos singulariza enquanto indivíduos que vivenciam a vida de um modo único. Por outro lado, universaliza-nos, pois somente seres de sentido podem encontrar significação na comunicação com outro.

O estudo inicia apontando as muitas percepções construídas a partir do vivido por lideranças comunitárias e profissionais de saúde acerca dos sentidos da participação social, reconhecidos como conquista e direito construído social e historicamente associado ao engajamento/compromisso político. Freire (2001) destaca que a condição primordial para que um ser assuma um ato comprometido socialmente é a capacidade de agir e refletir, refletir sobre si e sobre o seu estar no mundo, associada a sua ação sobre o mundo e a transformação dele. A ação e a reflexão são constituintes e inseparáveis da práxis, maneira humana de existir.

Muitos elementos presentes nos discursos de lideranças comunitárias e profissionais de saúde corroboram o enunciado de Freire (2001) e estão associados à práxis e ao compromisso com a participação e a transformação social, a saber: a luta por políticas sociais, o comprometimento em busca de melhorias comunitárias, a ação/intervenção social, o movimento em benefício da sociedade, o protagonismo social, a construção coletiva e a mobilização.

Compreendendo a participação como uma expressão da potência humana, Brandão (2008) ressalta que participar diz respeito à capacidade de afetação nas relações e destaca uma associação significativa entre participação e afetividade ética e política, impensável sem a presença do outro, engajamento e atitude participativa dos sujeitos diante do mundo.

Seguem abaixo algumas falas destacadas de lideranças comunitárias e profissionais de saúde que confirmam tais consideraçōes iniciais.

Participação social é o comprometimento de pessoas, ou um grupo de pessoas que pensa e realiza atividades para melhoria da comunidade (LIDERANÇA A).

Eu acho que a participação social é as pessoas se tornarem protagonista (PROFISSIONAL A).

Participação social é quando a comunidade está mobilizada nas ações. Entendo a participação social como a mobilização da sociedade em busca de melhoras de 
serviços, não necessariamente só da saúde. Ela está participativa, ativa realmente nesses processos. Ela não está à parte, ela está junto, construindo junto com a gente (PROFISSIONAL B).

Conforme destaca Moroni (2009), a demanda pela participação sempre esteve presente nas lutas sociais em diferentes momentos e contextos de nossa história e seu significado encontra-se atrelado à intervenção política nas questôes que dizem respeito à vida concreta das pessoas, conforme apresentado nas falas a seguir.

Eu acho bastante importante e complexa essa questão e esse termo participação social, porque nós damos a voz de como é que a gente quer que as pessoas participem dentro da história. O Estado nada trás para que as pessoas participem (PROFISSIONAL C).

Participação social é Participação, ação, você intervir em busca não só na saúde, mas em todos os aspectos, saúde, educação, segurança. É uma forma coletiva em busca de melhorias para comunidade, seja para seu estado e seu país (PROFISSIONAL D).

Participação social é a gente participar mais dos grupos e sempre trazer mais melhoria para nossos grupos, pro nosso povo, pra nossa comunidade, participar das reuniões, sempre que for chamado nas nossas casas nós participarmos (LIDERANÇA B).

Os discursos permitem inferir que os sentidos da participação social encontram-se imbricados aos processos de luta social intrínsecos à dinâmica da comunidade. Sobre o termo "comunidade", adotou-se neste estudo uma concepção construída por Góis (2008), que a aponta como uma instância da sociedade com dinâmica própria e lugar de moradia, de permanência estável, de crescimento e de proteção da individualidade, cheio de contradições, mas de interesses comuns, que servem de construção das ações de moradores em relação ao lugar e ao conjunto da sociedade.

Para Góis (2008), a essência das comunidades está relacionada à construção de práticas coletivas e proteção do lugar em que vivem. As falas a seguir dialogam com tal perspectiva e complementam que a participação vem sendo construída através das gerações, sendo necessária a articulação com a perspectiva de sustentabilidade.

Eu vejo como trazer desenvolvimento para o bairro, melhoria para o nosso bairro. Cada um de nós sem ter que esperar muito por outros, podemos fazer uma pequena participação que será muito grande no futuro para as crianças, para as pessoas mais velhas, para as pessoas que precisam da gente. A gente também precisa muito dessas pessoas para aprender, para crescer, para desenvolver. Elas têm mais vida, já viveram mais, já sabem de muitas dificuldades que passaram (LIDERANÇA C). 
Essa participação social é fundamental para a gente crescer dentro do bairro, e o

bairro crescer junto com a gente, para que um dia a gente tenha um futuro melhor para nossas crianças. A gente tem que trabalhar nesse sentido, de melhorar o lugar onde a gente vive, onde a gente aprendeu a viver, aprendeu a crescer, a se desenvolver da sociedade (LIDERANÇA C).

As falas revelam um potencial de mudança existente no interior do lugar em que vivem. Nesse sentido, Góis (2008) destaca que as comunidades, por revelarem um "potencial de transição", podem apresentar condições para superar a pobreza e as desigualdades sociais.

A ideia de engajamento social e político associado à participação também vem atrelada a uma segunda percepção, que aponta a participação vinculada à ajuda e à solidariedade. Contudo, é importante problematizar que tipo de participação tem sido construída, pois compreensões atreladas ao assistencialismo, à ajuda e sempre na relação com "o outro" podem revelar relações de poder desiguais e fragilizar processos de construção da autonomia e cidadania, conforme evidenciam as falas a seguir.

Participação social é se engajar em buscar melhorias para outras pessoas, como ajudar essas pessoas a desenvolver o seu talento, a se encontrar, a tirar essas pessoas do submundo do crime, das drogas, fazer com que essas pessoas realmente se sintam pessoas de verdade, que a gente vê aí que muitas das vezes as pessoas estão perdidas porque não se encontram, não tem pessoas que ajudem, que dê uma palavra (LIDERANÇA C).

[...] participação social é isso procurar resolver os problemas que estão acontecendo no bairro e procurar resolver as situações das pessoas. Procurando ajudar, para que aquelas pessoas fiquem satisfeitas com seus objetivos (PROFISSIONAL B - ACS).

Outra percepção de profissional de saúde realiza uma interface entre participação e educação, historicamente pragmática e opressora:

[...] a gente não pode esquecer que durante todo o decorrer da história ou da vida, as pessoas são formadas para não participarem [...]. A gente tira pelo modelo educacional, onde a gente fica sentada, tem uma pessoa que fala, e aí quando passa o tempo a gente quer que as pessoas tenham uma voz ativa dentro da comunidade, onde nem foram ensinadas ou estimuladas. Mas também não quer dizer que pessoas que não tiveram nenhum contato com essa educação transformadora não possam ser lideranças. Mas tem todo um modelo que estimula a não participação social. Outra coisa é pensar na Participação social institucionalizada e na não institucionalizada, porque a gente sempre pensa nos conselhos, nos movimentos, mas a Participação não precisa ter essa burocracia, ou as pessoas até não entram por tanta burocracia [...] (PROFISSIONAL E). 
Demo (1996) discorre sobre uma educação comunitária e participativa, em que, por um lado, o Estado se compromete a sustentar a necessária rede de atendimento, e por outro, a sociedade a assume como conquista sua. As lideranças apontam "caminhos" para tecer essa rede participativa.

Participação social não é só você pegar e ensinar alguém a tocar um violão, jogar futebol. Participação social é ajudar essa pessoa a viver uma vida como gente, como uma pessoa que esteja ali engajada no meio social, tipo, é não só ensinar, como também mostrar essa pessoa, o lado principal que é a educação, essa pessoa a se educar, a se encontrar nesse meio social. Participação social é um pouco de ensinar e de mostrar a disciplina, porque às vezes a gente trabalha com pessoas, com crianças, e a gente vê que sabe jogar futebol, sabe cantar, é um artista, mas às vezes não tem aquela educação - a oportunidade (LIDERANÇA C).

Freire (1987) nos faz pensar sobre como a Educação tem implicações nos processos de participação da sociedade. Em sua obra Pedagogia do Oprimido, afirma que quanto mais analisamos as relações educador-educandos na escola ou fora dela, parece que mais nos convencemos de que são fundamentalmente narradoras e dissertadoras. Nessa relação, implica um sujeito narrador - o educador e objetos pacientes, ouvintes - os educandos. Narra-se uma realidade parada e alheia à experiência existencial dos educandos. Nesse tipo de proposta educacional, o educador tem a tarefa de "encher" os educandos dos conteúdos de sua narração, conteúdos que são retalhos da realidade desconectados da totalidade que proporcionaria significação (FREIRE, 1987).

A narração, de que o educador é o sujeito, conduz os educandos à memorização mecânica do conteúdo e os transforma em "vasilhas" a serem "enchidas" pelo educador. Desta maneira, a Educação se torna um mero ato de depositar, em que os educandos são os depositários e o educador, o depositante. Eis aí a concepção "bancária" da educação que precisa ser superada por meio de uma educação problematizadora e dialógica, realizada como prática da liberdade, de acordo com Freire (1987).

As percepções apresentadas sobre participação social também evidenciaram significados múltiplos que estão intimamente agregados a sentidos. Não há como pensar em significados sem relacioná-los ao que dá sentido a sua produção no cotidiano das relações e das políticas de saúde.

[...] só tem um sentido, de buscar investigar, se manifestar. Hoje existe algo no Brasil, algo que não se via no Brasil, só em outros países, manifestações pacíficas. E isso dá direito a você reivindicar, buscar melhorias na saúde (LIDERANÇA C). 
Nessa perspectiva, os(as) participantes ressaltam, sobretudo, que o sentido da participação social na saúde relaciona-se com a própria construção sócio-histórica e coletiva do SUS, com a prevenção da saúde, com a busca por direitos diante das dificuldades/necessidades de saúde e com a transformação dessa realidade. Os discursos evidenciam que a participação social foi determinante para a construção do SUS, participação materializada a partir da coletividade e da produção de sentidos para a luta.

A participação social foi determinante no percorrer da história. Nós tivemos uma saúde privatista e não inclusiva. Essa participação fez com que um grande grupo se juntasse e fosse brigar nas grandes instâncias. No momento que a participação social não era efetiva, a gente estava em um processo ditatorial e mesmo assim as pessoas acreditaram naquele processo e foram e construíram com muito tensionamento. Só foi possível a construção do SUS, esse Sistema Único Brasileiro e público com a participação social e até hoje pensar nas políticas públicas é pensar o que é que a população quer, o que é que ela necessita, é ouvir, e estar construindo junto não tem essa coisa de determinar, é um processo sempre reflexivo, mas refletindo junto com quem usa, trabalha e constrói. Então essa participação bem completa, todas essas pessoas que fazem parte desse sistema estarem juntos nessa construção (PROFISSIONAL E).

Os sentidos expressos nos discursos de profissionais de saúde revelam que participar na saúde é "dividir coletivamente responsabilidades, seja de profissional, seja da comunidade, seja do poder público” (PROFISSIONAL D). Entretanto, apesar das conquistas com relação à participação, outras falas evidenciam que ainda há uma dificuldade da população em reconhecer-se "parte" da tessitura das políticas de saúde.

Eu acho que a participação social faz sim sentido para o SUS, mas ao mesmo tempo eu acho que a sociedade não entende o sentido que ela faz para as políticas públicas e para o SUS (PROFISSIONAL A).

A partir do momento que a comunidade se perceber, que as pessoas se perceberem participativas, entenderem que elas têm que participar, que elas fazem parte da saúde, que elas têm que ter a voz ativa [...] porque elas acham que não têm voz (PROFISSIONAL C).

A dificuldade de "sentir-se parte" da construção das políticas de saúde e, consequentemente, produzir sentido para participação parece ser um desafio para a sociedade em geral, como para profissionais de saúde, que ainda reproduzem práticas que fragilizam a autonomia de usuários em seu cotidiano, de acordo com fala a seguir: 
Atualmente a gente percebe ainda em pleno século XXI, que as pessoas não reconhecem isso, não reconhecem que têm esse direito, que têm deveres, os próprios profissionais também não reconhecem isso e às vezes acolhem a comunidade como se estivessem prestando um favor. Por conta disso é que nesses espaços que a gente precisaria dessa mobilização, dessa comunidade, porque eu acho que a força e a voz da população é que tem vez, que seria ouvida realmente, e a gente não tem (PROFISSIONAL F).

Por outro lado, há profissionais que constroem importantes sentidos para participação na saúde, a partir de sua prática e dos desdobramentos dela, a exemplo do ACS. Um dos sujeitos da pesquisa afirmou que "é gratificante participar do SUS. A gente vai lá naquela casa realmente que a pessoa está lá doente, que às vezes nem sabe dos seus direitos. A gente vai lá, orienta. E quando ela realmente vai lá e vai atrás do seu direito a gente se sente até bem" (PROFISSIONAL C ACS). Brandão (2008) contribui com essa discussão ao destacar que "o sentido maior da participação é conferir sentido a nossa própria existência como sujeitos que rejeitam o nonsense de toda desmesura e afirmam o desejo irredutível de presentificar-se no mundo" (BRANDÃO, 2008, p. 176).

Profissionais de saúde reconhecem que a participação na saúde é um direito legal e social inserido nas políticas do SUS e que seu sentido é garantir que possa ser construída de maneira compartilhada. Destacam que o sentido é: "eles irem atrás dos direitos deles e saber que isso é direito deles e que isso está legislado" (PROFISSIONAL G) ou que é “a participação da comunidade, das pessoas, dentro dos problemas [...] E tentar junto, resolver, junto com a participação deles. Ou seja, eles têm o direito de opinar” (PROFISSIONAL H).

Por meio dos discursos, evidenciamos ainda que há uma fragilidade na construção de sentidos para espaços institucionalizados de participação, a exemplo dos Conselhos de Saúde.

A gente tem esses espaços de conselho, que teria que ter essa participação social bem ativa, e esses espaços acabam sendo bem esvaziados porque a população ainda não reconhece seu espaço dentro desse sistema, acho que não só na saúde, mas de todos os espaços (PROFISSIONAL F).

Demo (1996) destaca que a participação não é um hábito em nossas vidas. Faz parte da história da humanidade receber de maneira prática as coisas dos outros. De acordo com Oliveira e Pinheiro (2010), muitas pesquisas apresentam fatores que dificultam a participação e o controle social, tais como o autoritarismo presente na sociedade e nas instituições brasileiras. 
Embora a Lei no 8.142/90 garanta a participação social no SUS e os profissionais destaquem que ela "é bem importante no sentido dessa construção coletiva” (PROFISSIONAL I), isso por si só não garante práticas democráticas na construção das políticas. Ainda segundo Oliveira e Pinheiro (2010), os vários sentidos e as práticas de participação interferem na relação entre Estado e sociedade civil, bem como nas decisões que definem os destinos da coletividade.

A participação, legitimada como direito e princípio do SUS, conforme destacado por lideranças comunitárias, só adquire sentido quando é percebida como divisão de responsabilidades, colaboração, envolvimento com a construção das políticas de saúde, implicação com o SUS, conquista, união e mobilização pela saúde. Elas apontam inclusive desdobramentos que podem potencializar o sentido de participar socialmente das políticas de saúde, inicialmente a partir da identificação de causas e dificuldades e posteriormente por meio de reinvindicações coletivas em busca de direitos:

Eu acredito que seja identificar as dificuldades e com isso estudar soluções e melhorias. A gente só vai atrás das soluções quando tem os problemas. Então primeiro tem que identificar as causas, as dificuldades, para buscar soluçôes e as melhorias (LIDERANÇA A).

É hora de todo mundo se juntar, se reunir e ir para as ruas. Porque a gente tem condições de fazer isso. Se não está dando certo, se você for no posto e não tiver remédios, você pergunta porque, se não tem resposta, continua perguntando, se não encontrar nenhuma resposta, nem depois de outras perguntas, vamos se reunir gente, nós somos a comunidade, nós temos voz e vez, nós somos a força, eles precisam de nós. A gente tem que mostrar quem somos (LIDERANÇA C).

$\mathrm{Na}$ visão de lideranças, a participação adquire sentido de prevenção da saúde a partir de movimentos cotidianos de reflexão e mobilização para transformações comunitárias e potencialização dos investimentos públicos na saúde:

O grande sentido de tudo isso é a prevenção. E a partir do momento que a gente senta num grupão desse e que a gente pode decidir sobre a nossa comunidade. Tem uma importância tão grande que a gente não tem noção. A gente não pode tudo, não pode abraçar tudo de uma vez, mas se a gente sentar e organizar, tudo vai sair legal. Porque o problema do meu vizinho é nosso também. Esse é o grande sentido da participação social dentro do nosso bairro, dentro da nossa própria casa, é a gente se organizar para trabalhar a prevenção. Esses grupos, esses sonhos que sejam construídas coisas que melhorem mais a saúde dessa juventude que não seja cadeia, quem pode construir isso somos nós (LIDERANÇA D). 
Já para profissionais de saúde, os sentidos da participação na saúde também vão sendo tecidos desde o momento de planejamento das ações e serviços de saúde. Dessa forma, inserir e implicar profissionais e usuários do SUS em todas as práticas de cuidado à saúde parece ser elemento imprescindível para uma política democrática, participativa e significativa para os sujeitos envolvidos.

Eu acho que é interessante quando você fala em política conhecer o que é que interessa para um grupo especifico, por exemplo, quando se fala em saúde do homem, até nos planejamentos locais quando a gente vai trabalhar sobre isso. [...] a gente tem que quando pensar em formular políticas, trabalhar com representação para a gente saber realmente o que eles querem. Outro grupo que eu acho muito interessante você trabalhar e ter essa participação é o adolescente que não chega até nós, e que nós na verdade temos que ir até eles ou então é saber realmente todas as vezes que a gente for formular ou pensar em alguma ação a gente trabalhar em conjunto. Porque se a gente não construir espaços ou na verdade ir até esse grupo a gente não atinge as nossas ações, vão ser em vão [...] (PROFISSIONAL F).

De acordo com Demo (1996), há uma tendência histórica da sociedade em organizar-se através de polarizações hierárquicas predominando a postura vertical, de cima para baixo. Assim, é peculiar que haja um lado minoritário que comanda e outro que é comandado, questão que pode encontrar-se de maneira implícita na fala acima descrita e que revela ainda fragilidade na organização dos serviços de saúde.

Diante do contexto, faz-se necessário refletir sobre a incorporação da participação em saúde nas práticas cotidianas da ESF, questão complexa na medida em que depende da interação de fatores histórico-políticos e sócioeconômico-culturais, relacionados aos gestores, comunidade e trabalhadores de saúde. Trata-se de romper com paradigmas históricos de organização e materialização dos cuidados à saúde centralizados em gestores e profissionais, superar práticas medicalizantes, normativas, fragmentadas e punitivas.

\section{Considerações finais}

As falas revelam que a participação social foi elemento primordial para a construção do SUS, sistema materializado a partir da responsabilização compartilhada de profissionais de saúde, gestores e usuários. Entretanto, apesar de sublinharem conquistas com relação à participação social no SUS, ainda há dificuldade da comunidade em reconhecer-se nesse processo, questão por vezes dificultada pela 
maneira como foram desigualmente organizados ao longo da história os serviços de saúde, fragilizando a promoção da autonomia.

Esta pesquisa proporcionou aproximação aos sentidos da participação na ESF e apresentou entraves que são inerentes à vida social e política do país e estão diretamente relacionados à construção do SUS. Os desafios da participação social na saúde e que permeiam as duas décadas de SUS e de ESF hoje são pautas que devem constar como prioridade nas agendas governamentais e da sociedade com vistas a tensionar a materialização de um sistema universal, democrático, único e que possa acolher com justiça social a todos que dele necessitam.

Em Vila União, munícipio do Ceará investigado, apesar dos avanços nos processos participativos, a comunidade parece ainda não estar inserida efetivamente no processo de construção das açôes e serviços de saúde. A dificuldade no diálogo muitas vezes ainda desigual entre comunidade e gestores da saúde enfraquece o agir consciente e a construção de propostas de transformação da realidade no âmbito da ESF de Vila União.

Apesar das limitações desta pesquisa, que se configurou como um estudo de caso realizado em território específico, não contemplando a realidade integral do SUS, os "achados em campo" evidenciam que a ESF tem um potencial de estimular a organização comunitária e a autonomia de famílias. Para isso, é preciso encarar os novos desafios postos no cotidiano da ESF, tendo a compreensão de que o exercício da democracia demanda tempo, é processual. Além disso, a participação social requer mobilização coletiva, não no sentido de aglutinar pessoas apenas com fins reivindicatórios, mas como energias a serem canalizadas por objetivos comuns, conforme destaca Gohn (2011), e as lideranças comunitárias e profissionais de saúde participantes deste estudo.

Considera-se imprescindível a construção de um novo modelo de atenção pautado na participação social e que aponte para uma rede de compromissos e laços de afetividade potentes com o SUS e na ESF, que possa implicar, sobretudo, a comunidade e outros setores envolvidos no cuidado à saúde na produção de respostas ou propostas ousadas de enfrentamento às iniquidades na saúde. Conforme destaca Nepomuceno (2009), é necessário construir um modelo de atuar com a comunidade, em que a dialogicidade e ação transformadora sejam construídas na corresponsabilização. 
Nessa perspectiva, almeja-se que trabalhadores, usuários e gestores possam buscar referências e sentidos transformadores capazes de tensionar lógicas instituídas e burocráticas ainda presentes nos serviços de saúde e que inviabilizam a participação social. Precisamos de um "novo modelo assistencial, centrado no usuário e na defesa radical da vida” (MERHY, 2013, p. 78), um modelo que possa romper com a centralidade nos problemas e produzir responsabilidade pelos atos cuidadores na saúde. ${ }^{1}$

\section{Referências}

ANDRADE, L. O. M. et al. Atenção Primária à Saúde e Estratégia Saúde da Família. In: CAMPOS, G. W. S. et al. (Org.). Tratado de Saúde Coletiva. 2. ed. rev. aum. São Paulo: Hucitec, 2012. p. 845-902.

BARDIN, L. Análise de conteúdo. Rio de Janeiro: Persona, 1977. . Análise de conteúdo. Trad. Luís Antero Reto e Augusto Pinheiro. Lisboa: Edições 70, 2002.

BRANDÃO, I. R. Afetividade e participaçāo na metrópole: Uma reflexão sobre os dirigentes de ONGs da cidade de Fortaleza. 2008. 220 f. Tese (Doutorado em Psicologia Social) Pontifícia Universidade Católica de São Paulo, São Paulo, 2008.

BRASIL. Ministério da Saúde. Nota Técnica. Informações sobre as açôes e programas do Departamento de Atenção Básica. Estado: Ceará. Competência: abril de 2014. Disponível em: <http://dab2.saude.gov.br/dab/sistemas/notatecnica/frmListaMunic.php >. Acesso em: 15 jun 2014.

. Ministério da Saúde. Secretaria de Atenção à Saúde. Departamento de Atenção Básica. Politica Nacional de Atenção Básica. Brasília: Ministério da Saúde, 2012.

CRUZ NETO, O.; MOREIRA, M. R.; SUCENA, L. F. M. Grupos focais e pesquisa social qualitativa: o debate orientado como técnica de investigação. In: Encontro da Associação Brasileira de Estudos Populacionais, 13., Ouro Preto, 2002. Disponível em: <http:// www.moodle.ufba.br/file.php/12824/Texto_Pesquisa_Qualitativa.pdf>. Acesso em: 10 de jul. 2015.

DEMO, P. Participação é conquista: noçōes de política social participativa. 3. ed. São Paulo: Cortez, 1996.

ESCOREL, S. História das Políticas de Saúde no Brasil de 1964 a 1990: do golpe militar à Reforma Sanitária. In: GIOVANELLA, L. et al. (Org.). Políticas e sistema de saúde no Brasil. Rio de Janeiro: Fiocruz, 2008.

FREIRE, P. Educação e mudança. 24. ed. São Paulo: Paz e Terra, 2001. Pedagogia do oprimido. Rio de Janeiro, Paz e Terra, 1987. (O mundo, hoje, v. 21). 
GIOVANELlA, L.; MENDONÇA, M. H. M. Atenção Primária à Saúde. In:

GIOVANELlA, L. et al. (Org.). Políticas e sistema de saúde no Brasil. Rio de Janeiro: Fiocruz, 2008. p. 575-626.

GOHN, M. G. Conselhos gestores e participação sociopolítica. 4a. ed. São Paulo: Cortez, 2011. v. 32 .

GÓIS, C. W. L. Saúde Comunitária. Pensar e fazer. São Paulo: Aderaldo \& Rothschild, 2008.

INSTITUTO BRASILEIRO DE GEOGRAFIA E ESTATÍSTICA. IBGE Cidades.

Disponível em: <http://cidades.ibge.gov.br/xtras/perfil.php?lang=\&codmun=231290\&se arch=ceara|sobral> Acesso em: 12 out. 2013.

LAKATOS, E. M.; MARCONI, M. A. Fundamentos de metodologia científica. São Paulo: Atlas, 2005.

MARTINELli, M. L. (Org.). Pesquisa qualitativa: um instigante desafio. São Paulo: Veras, 1999.

MENEZES, J. S. B. M. O Conselho Nacional de Saúde na atualidade: reflexões sobre os limites e desafios. In: BRAVO, M. I. S.; MENEZES, J. S. B. (Org.). Saúde, Serviço Social, Movimentos Sociais e Conselhos. São Paulo: Cortez, 2012. p. 253-272.

MERHY, E. E. A perda da dimensão cuidadora na produção da saúde: uma discussão do modelo assistencial e da intervenção no seu modo de trabalhar a assistência. In: FRANCO, T. B.; MERHY, E. E. (Org.). Trabalho, produção do cuidado e subjetividade em saúde: textos reunidos. 1. ed. São Paulo: Hucitec, 2013. p. 68-94.

MORONI, J. A. O direito à participação no governo Lula. In: AVRITEZ, L. (Org.). Experiências Nacionais de participação social. São Paulo: Cortez, 2009. p. 107-141.

MINAYO, M. C. S. Ciência, técnica e arte: o desafio da pesquisa social. In: (Org.). Pesquisa Social: teoria, método e criatividade. 18. ed. Petrópolis: Vozes, 2001.

. O desafio do conhecimento: pesquisa qualitativa em saúde. São Paulo: Hucitec, 2006.

. O desafio do conhecimento: pesquisa qualitativa em saúde. 11. ed. São Paulo: Hucitec, 2008.

NEPOMUCENO, L. B. Para atuar com a comunidade: estudo sobre a relação entre participação comunitária e Estratégia de Saúde da Família do SUS no Bairro Terrenos Novos em Sobral, Ceará. 2009. 206 f. Dissertação (Mestrado em Psicologia) - Programa de Pós-Graduação em Psicologia, Universidade Federal do Ceará Fortaleza, 2009. Disponível em: http://www.repositorio.ufc.br/handle/riufc/1679. Acesso em: 18 Mar. 2013.

OLIVEIRA, L. C.; PINHEIRO, R. A participação nos conselhos de saúde e sua interface com a cultura política. Ciênc. saúde coletiva, Rio de Janeiro, v. 15, n. 5, ago. 2010. Disponível em: <http://www.scielo.br/scielo.php?script=sci_arttext\&pid=S141381232010000500020\&lng=en \&nrm=iso >. Acesso em: 26 nov. 2012. 
SOARES, R. C. A racionalidade da contrarreforma na política de saúde e o Serviço Social. In: BRAVO, M. I. S.; MENEZES, J. S. B. (Org.). Saúde, serviço social, movimentos sociais e conselhos. São Paulo: Cortez, 2012. p. 293-306.

YIN, R. K. Estudo de caso: planejamento e métodos. Porto Alegre: Bookman, 2001.

\section{Nota}

${ }^{1}$ F.A. Lima participou da elaboração do projeto de pesquisa, revisão bibliográfica, pesquisa de campo, análise e interpretação dos dados, redação e revisão crítica do artigo. P.A.Galimbertti participou da orientação do projeto de pesquisa, revisão bibliográfica, pesquisa de campo, análise e interpretação dos dados, revisão crítica e aprovação da versão final do artigo. 
Senses of social participation in health for community leaders and professionals of the Family Health Strategy in the territory of Vila Uniao, Sobral-CE, Brazil

The article presents a case study with a qualitative approach aimed to analyze the meanings of social participation in health among community leaders and professionals of the Family Health Strategy (ESF) in the territory of Vila Uniao in Sobral, Ceara state, Brazil. Data were collected through focus groups and analyzed using content analysis techniques. The results showed that the socially and historically produced meanings of social participation, recognized as a conquest and a right, are associated with engagement, social transformation, commitment to seeking community improvements, action / social intervention, social role, the collective construction and mobilization of community solidarity and liberating education. The research provided information on the meanings of participation in the ESF and on the barriers inherent in political life and are directly related to the construction of Brazilian National Health (SUS). We consider very important building a new model of care grounded in social participation and pointing to a network of commitments and ties of affection with a powerful SUS / ESF that could involve, especially, the community.

$>$ Key words: Social participation; Brazilian National Health System; primary care; family health. 